\title{
De Gustibus
}

\section{Через годы, через расстояния...}

\section{๑) Г.А. Герасимов}

\author{
Глобальная сеть по йоду, Мёртл Бич, США
}

\begin{abstract}
Медицина - наука древняя. В современном понимании врачебная профессия стала формироваться после того, как кровопускание в качестве универсального способа восстановления баланса телесных соков в организме было заменено более научными и менее калечащими методами. Но в медицинской практике случается так, что новые методы диагностики и лечения уживаются с весьма древними, а некоторые традиционные подходы, ранее не имевшие надежного обоснования, получают солидную научную поддержку. Этот исторический процесс напоминает течение воды в реке: быстрое в стремнине, медленное вдоль берегов и малоподвижное в тихих заводях, на дне которых можно найти принесенные паводками ветхие отбросы и разнообразный мусор. Все это находится в кругообороте - что-то исчезает в пучине, а что-то неожиданно всплывает на поверхность. Скандал с отзывом из аптечной сети в США препарата из измельченной и высушенной щитовидной железы свиней напомнил о том, что в клинической практике могут мирно уживаться средства, известные со времен древней китайской медицины, и препараты, появившиеся относительно недавно благодаря современной фармацевтике. Правда, при одной существенной оговорке: качество таких препаратов должно контролироваться столь же тщательно, что и новейших средств. Современные технологии позволили анализировать геном обитателей наших внутренних органов, составляющих микробиоту, что позволило реабилитировать ранее считавшееся антинаучным представление о дисбактериозе (дисбиозе). Например, кишечные бактерии способны конкурировать с организмом “хозяина" за селен и даже усугублять его дефицит, а также модулировать биодоступность йодтиронинов. Не исключено, что кишечный дисбиоз может быть одной из причин мальабсорбции тироксина. Обо всем этом и многом другом в очередной авторской колонке "De Gustibus".
\end{abstract}

Ключевые слова: щитовидная железа, тироксин, сауна, микробиом, дисбиоз, селен, фагоциты.

\section{Through years, across distances...}

\section{${ }^{\circ}$ Gregory A. Gerasimov}

Iodine Global Network (IGN), Myrtle Beach, USA

\begin{abstract}
Medicine is an ancient science. In the modern sense, the medical profession began to form after bloodletting as a universal way of restoring the balance of bodily juices was replaced by more scientific and less crippling methods. But in medical practice it often happens that new methods of diagnosis and treatment get along with very ancient ones, and some traditional approaches, that previously had no reliable justification, receive solid scientific support. This historic process closely resembles the flow of water in a river: fast in the rapids, slow along the shores and sedentary in quiet creeks, at the bottom of which one can find shabby garbage brought by floods. All this is in a circuit something disappears in the abyss, and something suddenly floats to the surface. The scandal in the USA with the recall of a medicine made from desiccated and dried porcine thyroid gland reminded us that some concoctions, which have been known since the times of ancient Chinese medicine, and drugs that appeared relatively recently thanks to modern pharmacology can easily coexist in clinical practice. With one essential caveat: the quality of such concoctions should be controlled as carefully as the newest drugs. Modern technologies have allowed us to analyze the genome of the inhabitants of our internal organs, that constitute the human microbiome. This made it possible to rehabilitate the concept of dysbacteriosis (dysbiosis), which was previously considered anti-scientific. For example, intestinal bacteria are able to compete with the host organism for selenium and even capable of aggravating its deficiency, as well as modulating the bioavailability of iodothyronines. It is possible that intestinal dysbiosis may be one of the causes of thyroxine malabsorption. All these and much more in this column "De Gustibus".
\end{abstract}

Keywords: thyroid gland, thyroxin, sauna, microbiome, dysbiosis, selenium, phagocytes.

В середине августа 2018 г. новостью №2 (по количеству обращений) на популярном англоязычном интернет-сайте для врачей "Medscape” была информация об отзыве компанией "Westminster Pharmaceutical” из аптечной сети в США препарата гормонов щитовидной железы в связи с возможным загрязнением производимого в Китае сырья [1].
Понятно, что в разгар торговой войны между двумя сверхдержавами эта публикация вызвала многочисленные комментарии, по большей части не относящиеся к существу проблемы.

Только сравнительно небольшая часть читателей обратила внимание на то, что виновником скандала был не просто фармацевтический препарат, а “натур- 
продукт”, производимый из щитовидных желез свиней, а проблема возникла из-за низкой культуры заготовки биологического сырья на китайских скотобойнях. Препараты измельченной и высушенной щитовидной железы имеют довольно длительную историю. Считается, что впервые лечение микседемы препаратом из экстракта щитовидной железы было научно описано в Англии в 1891 г. ${ }^{1}$, и почти 100 лет это средство широко использовалось в клинической практике до тех пор, пока в 1970-80-х гг. не было заменено синтетическим L-тироксином.

Известно, что в США по количеству выписанных рецептов (120 млн в 2014 г.) тироксин находится на первом месте среди всех лекарственных препаратов, не считая, конечно, тех, что свободно можно найти на прилавках аптек. На этом огромном рынке всегда может найтись место такому нишевому средству, как лекарственный продукт из высушенной и измельченной щитовидной железы свиней.

Тайна популярности препарата отчасти кроется в буквах “NP”, которые означают “натуральный продукт”, что для определенной группы потребителей является однозначной альтернативой ненавистной “химии”. Поскольку в тиреоидных препаратах, производимых из биологического сырья, присутствует не только тироксин $\left(\mathrm{T}_{4}\right)$, но и трийодтиронин $\left(\mathrm{T}_{3}\right)$, они также могут оказаться предпочтительными для немалого числа пациентов с гипотиреозом и возможным нарушением конверсии $\mathrm{T}_{4}$ в $\mathrm{T}_{3}$. Так антикварный препарат получил новую жизнь.

В 2013 г. было опубликовано двойное слепое перекрестное рандомизированное исследование, в котором “натуральный” тиреоидный препарат (Armor) сравнили с синтетическим L-тироксином (Syntroid) [2]. Авторами не было обнаружено существенных различий в динамике исчезновения симптомов гипотиреоза и показателях нейрофизиологических тестов между двумя группами. Вместе с тем пациенты на “натурпродукте" потеряли в среднем на 2,86 фунта (около 1,3 кг) больше веса, чем лечившиеся L-тироксином. После завершения эксперимента почти половина (49\%) пациентов предпочла продолжить лечение "натуральным" средством, 13\% L-тироксином, а 23\% не увидели различий между препаратами. Интересно, что у пациентов, лечившихся препаратом из свиных щитовидных желез, уровни ТТГ и $\mathrm{T}_{3}$ в крови были достоверно выше, $\mathrm{a}_{4}$ и свободного $\mathrm{T}_{4}-$ ниже по сравнению с группой на L-тироксине.

\footnotetext{
${ }^{1}$ Одна из первых американских пациенток начала лечение таким препаратом в 1891 г. и продолжала его принимать 52 года спустя в возрасте 84 лет. Ссылка на https://en. wikipedia.org/wiki/Desiccated_thyroid_extract.
}

В своем комментарии к этой статье [3] главный редактор журнала Американской тиреоидологической ассоциации (ATA) “Clinical Thyroidology” Джером Хиршман отметил, что в конце 1980-х гг. почти $20 \%$ пациентов с гипотиреозом в США все еще использовали тиреоидные препараты, полученные из щитовидных желез животных. Однако вскоре эти препараты были почти полностью вытеснены синтетическим L-тироксином. Дело дошло до того, что некоторые американские эндокринологи категорически отказываются выписывать рецепты на "натуральные” тиреоидные препараты, а чрезмерно настоятельным пациентам рекомендуют найти другого врача.

Автор комментария вместе с тем полагает, что в таком радикализме нет нужды, а выписка по просьбе пациентов “натуральных” тиреоидных препаратов не более рискованна, чем назначение небольших доз $\mathrm{T}_{3}$ тем пациентам, у которых клинические симптомы гипотиреоза персистируют на фоне лечения L-тироксином.

Приведенный выше пример, как мне кажется, является хорошей иллюстрацией того, что в клинической практике нынче могут мирно уживаться средства, известные с дремучих времен (по некоторым источникам, высушенная щитовидная железа использовалась еще в древней китайской медицине [4]), и препараты, появившиеся относительно недавно благодаря современной фармацевтике. Правда, при одной существенной оговорке: качество древних препаратов должно контролироваться столь же тщательно, что и новейших средств. Например, содержание $\mathrm{T}_{4}$ и $\mathrm{T}_{3}$ в препаратах из высушенных щитовидных желез свиней производители сегодня оценивают методом масс-спектрометрии (а не просто по содержанию йода, как того требует Фармакопея США), при этом вариация содержания активного вещества в таблетке не превышает 5 мкг.

Медицина - профессия древняя. На протяжении тысячелетий с переменным успехом ее практиковали шаманы, жрецы, поводыри медведей на ярмарках (пример изображен на рис. 1), брадобреи и мозольные операторы при банях и лишь сравнительно недавно - врачи.

В современном понимании врачебная профессия стала формироваться после того, как кровопускание в качестве универсального способа восстановления баланса телесных соков в организме было заменено более научными и менее калечащими методами. Но прогресс медицинской науки - это не только дистилляция врачебного опыта путем возгонки и конденсации чистого знания.

На мой взгляд, этот процесс больше напоминает течение воды в реке: быстрое в стремнине, медлен- 


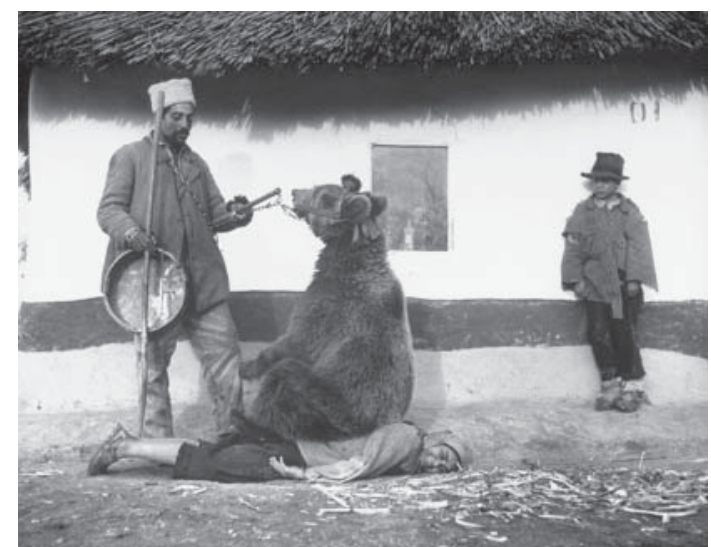

Рис. 1. Лечение боли в спине с помощью медведя (Румыния, 1946 г. $)^{2}$

ное вдоль берегов и малоподвижное в тихих заводях, на дне которых можно найти принесенные паводками ветхие отбросы и разнообразный мусор. Все это находится в кругообороте - что-то исчезает в пучине, а что-то неожиданно всплывает на поверхность.

То же случается и в медицинской практике новые методы диагностики и лечения часто уживаются с традиционными, а некоторые традиционные подходы, ранее не имевшие надежного обоснования, получают солидную научную поддержку.

Вот вам и пример: пару абзацев выше я уже упоминал баню как важное с исторической точки зрения учреждение первичной медицинской помощи. Поколения наших предков видели в бане не только чистилище, но и возможность поправить свое здоровье. И, как показало недавно опубликованное исследование финских ученых [5], целебные свойства сауны вполне могут иметь научное подтверждение.

Авторы провели анализ литературы по базам данных MEDLINE и EMBASE (включая рандомизированные, нерандомизированные и обсервационные исследования) эффекта финской сауны на показатели здоровья любителей хорошего пара. Из исследования в силу недостатка сведений были исключены другие виды бань (турецкая, русская, японская и др.). Согласно данным литературы, для достижения терапевтического эффекта температура финской бани должна была быть в пределе от 80 до $100{ }^{\circ} \mathrm{C}$, а относительная влажность - от 10 до 20\%. Посещение бани также не могло быть спорадическим явлением: по утверждению авторов обзора, “финны посещают баню не реже 1 раза в неделю при средней частоте 2-3 раза в неделю”.

Анализ литературы показал многочисленные положительные эффекты регулярного и достаточно

\footnotetext{
${ }^{2}$ From: 30 captivating historical photographs that you need to see. https://brightside.me/.
}

длительного посещения сауны: это снижение риска и геморрагического инсульта, и внезапной смерти от сердечных болезней. У частых посетителей сауны устойчиво падало систолическое и диастолическое давление, а частота артериальной гипертензии у мужчин в среднем снижалась на 47\% (при сроке наблюдения почти 25 лет!). Уменьшался риск деменции и болезни Альцгеймера, улучшалась эндотелиальная функция, снижался окислительный стресс и воспаление, и прочая, прочая, прочая...

Но терапевтическое и профилактическое влияние сауны имело и существенное ограничение. Чтобы снизить, например, риск деменции, недостаточно было просто посещать сауну по воскресеньям, а нужно было ходить в нее как на работу - от 4 до 7 раз в неделю. Авторы обзора не зря утверждают, что “физиологическую реакцию на регулярное посещение сауны можно сравнить со средней и даже интенсивной физической нагрузкой, такой как ходьба" [6]. Недаром ведь говорят, что сохранение здоровья - это тяжкий труд.

Исчезнув было в пучине забвения, вновь всплыло на поверхность страдание, известное ранее как “дисбактериоз”, а ныне чаще именуемое "дисбиозом" и определенное в приказе Минздрава России как "клинико-лабораторный синдром, связанный с изменением качественного и/или количественного состава микрофлоры кишечника" [7]. Согласно устойчивому мнению, представленному, например, в статье в русской Википедии ${ }^{3}$, дисбактериоз - это миф российской медицины.

Тут, мне кажется, мы сталкиваемся с семантической ${ }^{4}$ проблемой, суть которой была отражена еще в хулиганском стишке времен моего детства ${ }^{5}$ : есть некое патологическое состояние, от которого серьезно страдают многие миллионы пациентов, а вот подходящего названия ему найти пока не удается.

Ситуация радикально изменилась буквально за последнее десятилетие. Современные технологии позволили ученым анализировать геном обитателей наших внутренних органов, о которых большинство читателей, вероятно, предпочли бы вовсе не догадываться. Я имею в виду триллионы бактерий, вирусов и грибков, которые обитают практически во всех частях тела, включая те ткани, которые когда-то считались стерильными. Вместе они составляют человеческую микробиоту (совокупный генетический мате-

\footnotetext{
${ }^{3}$ https://ru.wikipedia.org/wiki/Дисбактериоз.

${ }^{4}$ Семантика (от греческого “обозначающий”) - раздел лингвистики, изучающий смысловое значение единиц языка.

${ }^{5}$ Вижу четко, вижу ясно, ну какой же тут секрет! Ведь такого не бывает: ж... есть, а слова нет.
} 

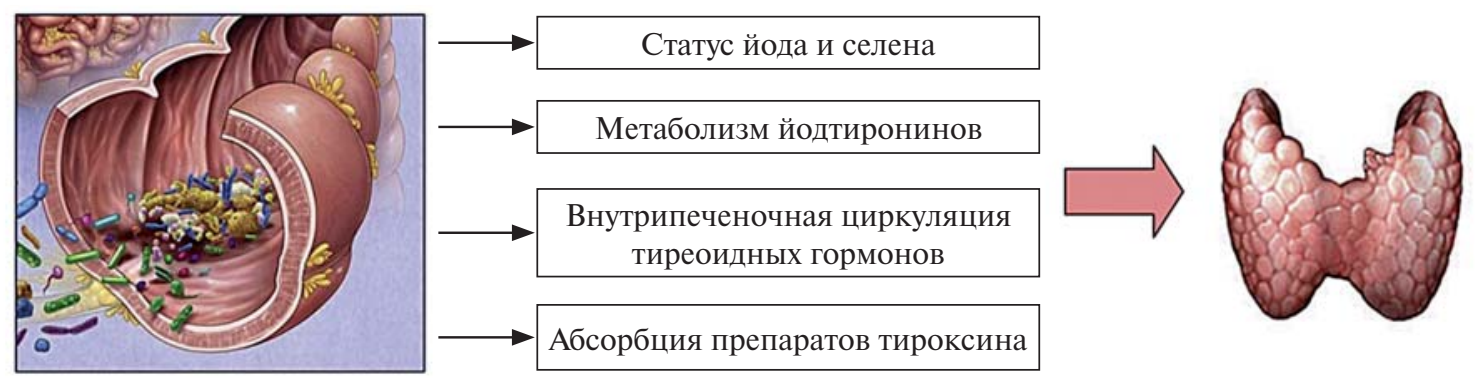

Рис. 2. Возможные пути влияния микробиоты на функциональное состояние щитовидной железы.

риал микробиоты называют также микробиомом), изучение которой является одной из самых перспективных, но вместе с тем крайне сложных проблем современной медицины. Это очень непростая задача: определить состав микроскопических обитателей каждого органа и уметь восстановить их правильный баланс, когда таковой оказывается нарушенным.

Дело в том, что количество бактериальных клеток и их генетического материала в организме человека намного превосходит число собственных клеток и генов. Взять, к примеру, пищеварительный тракт: в его нижнем отделе (кишечнике) примерно в 10 раз больше бактериальных, чем человеческих клеток. Генетическое разнообразие в кишечнике еще больше: бактериальная ДНК насчитывает в 100 раз больше генов, чем человеческая ДНК [8]. До недавнего времени традиционными методами микробиологии (типа культивации бактерий на чашке Петри) было просто невозможно определить от 20 до 60\% микробиоты. Это стало возможным только с помощью современных генетических методов.

Микробиота - это своеобразная "воронья слободка”, обитатели которой, по описанию авторов романа “Золотой теленок”, считались “своенравными и известны были всему дому частыми скандалами и тяжелыми склоками". Вместе с тем они были вполне способны к симбиозу, но при нарушении баланса это сожительство однажды закончилось большим пожаром. Впрочем, такой печальный исход нельзя считать типичным для здорового организма: обычно проблемы симбиоза и комменсализма ${ }^{6}$ в микробиоте решаются быстротекущим и бурлящим "кухонным скандалом” без столь уж тяжких последствий.

Проект микробиома человека (Human Microbiome Project) с бюджетом в 115 млн долларов, запущенный в 2008 г. Национальными институтами здравоохранения США для выявления и характеристики

\footnotetext{
${ }^{6}$ Комменсализм (буквально - сотрапезничество) - способ совместного существования разных видов живых организмов. Более подробно - https://ru.wikipedia.org/ wiki/Комменсализм.
}

микроорганизмов у здоровых и больных людей, можно в определенной мере сравнить с другим грандиозным проектом - изучением генома человека. Объем новой информации о роли микробиома в физиологии и патологии организма человека растет как снежный ком. Вот для примера только две недавние публикации, представляющие интерес для читателей эндокринологического научного журнала.

"С небольшой помощью от друзей" - название этой известной песни битлов ${ }^{7}$ авторы обзора о роли микробиоты в метаболизме тиреоидных гормонов вынесли в само название своей публикации [9]. В статье представлены данные о том, что кишечные бактерии могут, оказывается, конкурировать с "хозяином" за селен, поступающий в организм с пищей. А если селена в диете недостаточно, то наши маленькие друзья способные усугублять его дефицит. Микробиота кишечника может также играть важную роль в качестве резервуара или обменного пула тиреоидных гормонов, регулируя гомеостаз щитовидной железы и модулируя биодоступность йодтиронинов. Не исключено, что кишечный дисбиоз может быть одной из причин мальабсорбции препарата L-тироксина (рис. 2).

Другая научная статья также вызвала немалый ажиотаж и широко обсуждалась в зарубежных СМИ [10]. В этом канадском исследовании было изучено воздействие дезинфицирующих средств, широко используемых в домашних хозяйствах, на микробиоту младенческого кишечника и последующий риск избыточного веса у детей. Исследователи обнаружили, что дети в возрасте от 3 до 4 мес, живущие в домашних хозяйствах, где антимикробные дезинфицирующие средства использовались по меньшей мере еженедельно, имели более высокие уровни бактерий Lachnospiraceae в кишечнике, чем дети, в чьи домах дезинфицирующие средства использовались более редко или применялись экологически дружествен-

\footnotetext{
7 "With a Little Help from My Friends" - песня группы "The Beatles" из альбома "Sgt. Pepper's Lonely Hearts Club Band" (1967 г.).
} 
ные средства на основе уксуса. В возрасте 3 лет индекс массы тела у детей с более высоким уровнем Lachnospiraceae был выше, чем у детей из домохозяйств, где дезинфицирующие средства применялись реже чем раз в неделю.

Хотя бактерии Lachnospiraceae являются нормальным компонентом микробиоты кишечника, из исследований на животных известно, что более высокие уровни Lachnospiraceae связаны с избыточным весом и резистентностью к инсулину.

В комментарии к приведенной выше статье сотрудники отдела эпидемиологии Школы общественного здоровья Университета им. Джона Хопкинса в Балтиморе (США) Moira K. Differding и Noel T. Mueller признали, что результаты исследования являются вполне "биологически правдоподобными" [11]. Почему? Микроорганизмы, которые начинают заселять наш организм с периода младенчества, способны программировать и обучать иммунную и метаболическую системы в раннем детском возрасте. В ранее опубликованных исследованиях было показано, что нарушение естественного заселения кишечника младенца микроорганизмами (из-за родов кесаревым сечением, пренатального или постнатального лечения антибиотиками, кормления молочными смесями) также было связано с более высоким риском детского ожирения.

Кстати, термин “дисбиоз” (и даже “дисбактериоз”) стал общеупотребительным в зарубежной литературе и не считается "мифом российской медицины". Можно согласиться с критиками, что “дисбиоз” как название синдрома носит довольно расплывчатый характер и пока не внесен в МКБ. Но примерно то же можно сказать и о "метаболическом синдроме", хотя последний уже получил признание и номер в МКБ.

Несмотря на то что понятие "дисбиоз/дисбактериоз” широко, хотя и полуофициально, использовалось в советской и российской медицине еще до возвращения его в мировую научную литературу, это отнюдь не означало, что отечественные ученые были в этом направлении "впереди планеты всей" Но вот успехи и приоритет советских специалистов в области использования бактериофагов ${ }^{9}$ для лечения многих заболеваний ни у кого на Западе не вызывают сомнений [12].

В США нынче около 2 млн пациентов имеют устойчивость к основным антибиотикам и, по оценкам, 23 тыс. человек умирают от инфекций, которые

\footnotetext{
${ }^{8}$ Слова из песни Ю. Визбора “Рассказ технолога Петухова”.

${ }^{9}$ Бактериофа́ги, или фа́ги (от древнегреческого “пожираю”) - вирусы, избирательно поражающие бактериальные клетки. Чаще всего бактериофаги размножаются внутри бактерий и вызывают их лизис.
}

антибиотики победить не могут. В силу исторических причин после широкого внедрения в медицинскую практику антибиотиков от лечения бактериофагами в США отказались еще в 1940-х гг., признав этот метод небезопасным и громоздким. До сих пор практическое использование бактериофагов не получило официального разрешения от Администрации по лекарствам и пищевым продуктам США. Вместе с тем в СССР и нынешних постсоветских странах продолжали применять терапию бактериофагами и накопили в этом плане немалый опыт. Например, в России зарегистрированы и применяются 13 медицинских препаратов на основе фагов.

Помню, пару лет тому назад при очередном посещении Тбилиси я поселился в гостинице, напротив которой располагался центр по лечению бактериофагами. Об этом я узнал от американцев, которые жили в этом отеле и проходили лечение в этом центре. Про эффективность лечения в этом учреждении сказать ничего не могу: до сих пор жалею, что поленился зайти и обсудить с коллегами их опыт.

Так как эффективных методов борьбы с лекарственной устойчивостью (кроме разработки новых более мощных антибиотиков) пока не предвидится, а проблема уже принимает опасный оборот, у меня нет сомнений в том, что лечение бактериофагами найдет свое место в современной медицине. Однако на новые разработки потребуется немало времени и существенные затраты. Кроме того, по мнению западных экспертов, строгое лекарственное регулирование в США и Европе, вероятно, затормозит широкое использование фаговой терапии на многие годы вперед. Другая важная причина, по которой фаги не нашли широкого использования, заключается в том, что “Большая фарма" пока не может понять, как обеспечить интеллектуальную и патентную защиту препаратов на основе фагоцитов, без чего невозможно получить прибыль и окупить огромные расходы на научные разработки [13]. Но в 2018 г. в США уже открылись две биотехнологические компании, начавшие клинические испытания бактериофагов и имеющие большие планы на будущее.

Одну из них - Adaptive Phage Therapeutics - opганизовал 80-летний доктор Карл Меррилл, который до выхода на пенсию занимался изучением бактериофагов в Национальных институтах здоровья, но не мог продвинуться дальше экспериментальных разработок из-за регуляторных барьеров. Теперь он прервал заслуженный отдых, чтобы попытаться внедрить лечение бактериофагами в практику [14].

Впрочем, история с забытым было, но всплывшим вновь из глубин истории методом лечения инфекций бактериофагами только начинает раскручиваться. Будущее покажет, способны ли будут рос- 
сийские медики воспользоваться полученной форой или это начальное преимущество останется нереализованным. Обидно будет, если вместо разработки средства для лечения суперинфекций усилия будут направлены на гомеопатическую реинкарнацию тиреоидина $^{10} \ldots$

\footnotetext{
${ }^{10}$ http://www.gomeo-patiya.ru/lekarstva/196/thyreoidinumpokazaniya-k-primeneniyu.html
}

\section{Список литературы [References]}

1. Medscape.com [Internet]. Brooks M. Thyroid tablets recalled in US because of impurity risk [cited 2018 Dec 30]. Available from: https://www.medscape.com/viewarticle/900606.

2. Hoang TD, Olsen CH, Mai VQ, et al. Desiccated thyroid extract compared with levothyroxine in the treatment of hypothyroidism: a randomized, double-blind, crossover study. J Clin Endocrinol Metab. 2013;98(5):1982-1990. doi: https://doi.org/10.1210/jc.2012-4107.

3. Hershman J. Patients with hypothyroidism taking desiccated thyroid extract lost weight as compared with an equivalent dose of levothyroxine. Clin Thyroidol. 2013;25:122-124.

4. Hetzel B. The story of iodine deficiency. An international challenge in nutrition. New York: Oxford University press; 1989.

5. Laukkanen JA, Laukkanen T, Kunutsor SK. Cardiovascular and other health benefits of sauna bathing: a review of the evidence. Mayo Clin Proc. 2018;93(8):1111-1121. doi: https://doi.org/10.1016/j.mayocp.2018.04.008.

6. Medscape.com [Internet]. MacReady N. Saunas linked to numerous health benefits [cited 2018 Dec 30]. Available from: https:// www.medscape.com/viewarticle/900044.
7. ОСТ 91500.11.0004-2003 Протокол ведения больных. Дисбактериоз кишечника. [OST 91500.11.0004-2003 Protokol vedeniya bol'nykh. Disbakterioz kishechnika. (In Russ.)]

8. Sommer F, Anderson JM, Bharti R, et al. The resilience of the intestinal microbiota influences health and disease. Nat Rev Microbiol. 2017;15(10):630-638. doi: https://doi.org/10.1038/nrmicro.2017.58.

9. Virili C, Centanni M. "With a little help from my friends" The role of microbiota in thyroid hormone metabolism and enterohepatic recycling. Mol Cell Endocrinol. 2017;458:39-43. doi: https://doi.org/10.1016/j.mce.2017.01.053.

10. Tun MH, Tun HM, Mahoney JJ, et al. Postnatal exposure to household disinfectants, infant gut microbiota and subsequent risk of overweight in children. CMAJ. 2018;190(37):E1097-E1107. doi: https://doi.org/10.1503/cmaj.170809.

11. Differding MK, Mueller NT. Are household disinfectants microbially mediated obesogens? CMAJ. 2018;190(37):E1095-E1096. doi: https://doi.org/10.1503/cmaj.181134.

12. Time.com [Internet]. Sifferlin A. Superbugs are nearly impossible to fight. This last-resort medical treatment offers hope [cited 2018 Dec 30]. Available from: http://time.com/5068513/superbugs-arenearly-impossible-to-fight/.

13. Parfitt T. Georgia: an unlikely stronghold for bacteriophage therapy. Lancet. 2005;365(9478):2166-2167. doi: https://doi.org/10.1016/s0140-6736(05)66759-1.

14. Businesswire.com [Internet]. Adaptive phage therapeutics - terminally ill patient successfully treated with bacteriophage [cited 2018 Dec 30]. Available from: https://www.businesswire.com/news/ home/20170426006880/en/Adaptive-Phage-Therapeutics--Terminally-Ill-Patient.

\section{Информация об авторе [Authors info]}

Герасимов Григорий Анатольевич, д.м.н., професcop [Gregory A. Gerasimov, MD, PhD, Professor]; e-mail: gerasimovg@inbox.ru; ORCID: https://orcid.org/0000-0002-6299-7219.

\section{Как цитировать [То cite this article]}

Герасимов Г.А. Через годы, через расстояния // Клиническая и экспериментальная тиреоидология. - 2018. T. 14. - № 3. - C. 122-127. doi: https://doi.org/10.14341/ket10002

Gerasimov G.A. Through years, across distances. Clinical and experimental thyroidology. 2018;14(3):122-127. doi: https://doi.org/10.14341/ket10002

Рукопись получена: 15.11 .2018

Received: 15.11 .2018
Рукопись одобрена: 03.12 .2018

Accepted: 03.12.2018 